\title{
Pengembangan Modul Berbasis STEM untuk Siswa SMP
}

\author{
Fanni Zulaiha*, Dewi Kusuma \\ Pendidikan Fisika, Universitas Nahdlatul Ulama Cirebon \\ *Email: fanni.zulaiha@gmail.com
}

Received: 9 November 2020; Accepted: 16 Desember 2020; Published: 17 Desember 2020

DOI: http://dx.doi.org/10.29303/jpft.v6i2.2182

\begin{abstract}
The importance of students owning 21st century skills and mastering the basics of science, engineering, technology and mathematics can be taught through STEM education program. One of the problems related to learning time allocation for Science subjects at schools can be solved by using modules. The purpose of this research was to produce appropriate STEM-based modules for junior high school students. This research used Research and Development $(R \& D)$ method. This research procedure adapted the $4 D$ development model proposed by Thiaragaraja. The sampling technique used was for one to one evaluation and small group evaluation with purposive sampling technique. The number of students for the one to one evaluation was 10 people and for the small group evaluation was 66 people. STEM-based modules for junior high school students were validated by content experts and linguists. Content experts measured the correctness and clarity of the content and the design of the module. The results of the content validation obtained a value of 0.93 with a very high category. The linguists measured the clarity of information, conformity with Indonesian rules and the use of language effectively and efficiently. The results of the language validation obtained a value of 1.00 with a very high category. Measuring the validity of this module was also measured using a questionnaire instrument of readability and practicality given to students. The analysis of the results of the readability questionnaire by students obtained a value of $87 \%$ with a very strong category, and the practicality questionnaire obtained a value of $80 \%$ with a strong category. Based on these data, the STEM-based module for junior high school students was declared fit for use.
\end{abstract}

Keywords: STEM; Module; Junior High School

\section{PENDAHULUAN}

Pendidikan diharapkan memberikan keterampilan dan soft skill kepada peserta didik untuk membentuk sumber daya manusia yang kompeten sehingga mereka dapat bersaing secara internasional. Adanya persaingan di era Masyarakat Ekonomi ASEAN (MEA) menghadirkan tantangan besar bagi negara-negara berkembang seperti Indonesia dalam meningkatkan daya saing produk dan tenaga kerja. Oleh karena itu, dibutuhkan berbagai upaya yang dapat mewujudkan harapan tersebut. Aspek terpenting dalam pembangunan suatu negara adalah pendidikan (Milaturrahman et al., 2017). Memasuki era revolusi industri 4.0, pendidikan secara khusus pada pembelajaran sains memiliki tanggung jawab untuk menciptakan manusia yang cerdas, bertanggung jawab, dan adaptif terhadap perkembangan zaman (Arnyana,
2018). Penguasaan dasar-dasar sains dan matematika diyakini juga harus dimiliki oleh setiap individu yang hidup di abad ke-21. Penguasaan dasar-dasar sains dan matematika dapat didapatkan melalui pendidikan STEM (Sains, Technology, Enginering, and Mathematics).

Pendidikan STEM merupakan gerakan global dalam praktik pendidikan yang mengintegrasikan berbagai pola integrasi untuk mengembangkan kualitas SDM yang sesuai dengan tuntutan keterampilan abad ke-21. Pembelajaran berbasis STEM merupakan salah satu wujud dari pembelajaran yang kompatibel dengan sistem kurikulum yang berlaku di Indonesia (Rustaman, 2016). Dalam konteks pendidikan dasar dan menengah, pendidikan STEM bertujuan mengembangkan peserta didik yang STEM literate. Pada pembelajaran STEM, peserta didik pada 
jenjang pendidikan dasar perlu lebih didorong untuk menghubungkan sains dan enginering. Selanjutnya pada jenjang pendidikan yang lebih tinggi perlu diberikan tantangan untuk melakukan tugas-tugas rekayasa otentik sebagai komplemen dari pembelajaran sains melalui kegiatankegiatan proyek yang mengintegrasikan sains, rekayasa, teknologi, dan matematika (Bybee, 2013).

Hasil studi pendahuluan tentang pendidikan STEM yang dilakukan oleh Peneliti di beberapa SMP Negeri Kota Cirebon menunjukkan bahwa belum dilakukannya pembelajaran Sains yang terintegrasi dengan rekayasa, teknologi, dan matematika. Waktu pembelajaran yang disediakan di sekolah dirasa tidak cukup untuk melakukan hal tersebut. Banyaknya materi yang harus disampaikan, dengan waktu yang terbatas, membuat guru hanya mengajar IPA menggunakan metode ceramah. Siswa juga merasa jenuh belajar IPA karena hanya berupa teori saja. Praktikum IPA rata-rata hanya satu kali dalam semester. Siswa merasa takut belajar IPA karena banyaknya teori dan rumusrumus yang harus dihapalkan.

Disamping permasalahan tersebut, kondisi pandemi COVID-19 yang terjadi sejak akhir tahun 2019 berdampak pada proses pembelajaran di sekolah (Dewi, 2020; Setiawan dan Mofassaroh, 2020). Berdasarkan Surat Edaran Nomor 15 Tahun 2020 tentang Pedoman Penyelenggaraan Belajar Dari Rumah, kegiatan pembelajaran di sekolah dan perguruan tinggi dilaksanakan dari rumah dalam bentuk pembelajaran luring dan daring. Kegiatan pembelajaran selama masa pandemic covid juga diatur dalam Keputusan Menteri Pendidikan dan Kebudayaan Republik Indonesia Nomor 719/P/2020 tentang Pedoman Pelaksanaan Kurikulum pada Satuan Pendidikan dalam Kondisi Khusus
(Menteri Pendidikan dan Kebudayaan RI, 2020).

Berdasarkan hal tersebut, peneliti melakukan penelitian pengembangan modul pembelajaran STEM yang dapat menarik siswa untuk lebih menikmati pembelajaran. Modul merupakan bahan ajar yang disusun secara sistematis dan menarik yang mencakup isi materi, metode, dan evaluasi yang dapat digunakan secara mandiri. Dengan menggunakan modul, siswa dapat belajar secara mandiri tanpa atau dengan bimbingan guru, adanya kontrol terhadap hasil belajar melalui penggunaan standar kompetensi dalam setiap modul yang harus dicapai oleh siswa, dan mereka menjadi lebih bertanggung jawab atas segala tindakannya. Diharapkan dengan semakin aktifnya siswa, maka semakin baik pula kualitas hasil belajar yang diperoleh (Setyowati, et al., 2013).

Bahan ajar secara langsung mempengaruhi pembelajaran yang akan diberikan oleh guru. Sehingga pemilihan bahan ajar pun sangat penting. Terdapat bukti yang kuat bahwa pemilihan bahan ajar lebih berdampak pada belajar siswa dibandingkan dengan efektivitas guru (Chingos, 2012). Pada penelitian ini, jenis bahan ajar yang digunakan adalah modul. Modul merupakan bahan ajar yang disusun secara sistematis dan menarik, mencakup isi materi, metode, evaluasi dan dapat digunakan secara mandiri (Depdiknas, 2007). Modul sebagai suatu unit materi kurikulum yang lengkap, dapat juga ditambah dengan pencapaian tugas yang lebih besar atau tujuan-tujuan jangka panjang yang akan sangat membantu para guru dan siswa dalam kegiatan pembelajaran (Yoda, et al., 2011). Menurut Smaldino, et al., (2014) Modul setidaknya terdiri atas tujuh komponen, yaitu:

a. Tujuan pembelajaran

b. Lembar evaluasi 
c. Keududkan dan fungsi modul dalam kesatuan program yang lebih luas

d. Lembaran kegiatan siswa, yang berisi substansi kompetensi yang akan dipelajari atau diantarkan

e. Lembaran kerja siswa

f. Kunci lebar kerja

g. Pedoman bagi guru.

STEM yang merupakan akronim dari Science, Technology, Engineering, dan Mathematics pertama kali diluncurkan oleh National Science Foundation Amerika Serikat pada tahun 1990-an sebagai sebagai tema gerakan reformasi pendidikan dalam keempat bidang disiplin tersebut untuk menumbuhkan angkatan kerja bidangbidang STEM, serta mengembangkan warganegara yang melek STEM (STEM literate), serta meningkatkan daya saing global Amerika Serikat (AS) dalam inovasi iptek (Smaldino, et al., 2014). Menurut Rustaman (2016), salah satu pola intergasi yang mungkin dilaksanakan tanpa melakukan restrukturisasi kurikulum pendidikan dasar dan menengah di Indonesia adalah menginkorporasikan konten enjiniring, teknologi, dan matematika dalam pembelajaran sains berbasis STEM, sebagaimana diilustrasikan dalam Gambar 1.

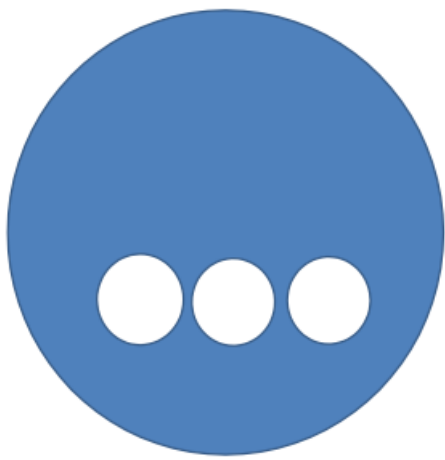

\section{SAINS STEM}

Gambar 1. Pendidikan Sains berbasis STEM

STEM memiliki tiga pendekatan dalam proses pembelajaran. Perbedaan antara masing-masing pendekatan terletak pada tingkat komponen STEM yang dapat diterapkan. Tiga pendekatan pendidikan STEM yang sering digunakan adalah pendekatan "silo" (terpisah), "tertanam" (embeded), dan pendekatan "terpadu" (terintegrasi). Dalam penelitian pengembangan ini, pendekatan STEM yang akan digunakan adalah pendekatan terpadu STEM. Pada penelitian ini pendekatan STEM yang akan digunakan yaitu "tertanam" (embeded).

STEM berorientasi pada kegiatan pemecahan masalah yang dihadapi secara nyata bertujuan agar siswa berlatih untuk menemukan solusi yang inovatif. Penggunaan STEM pada kegiatan pembelajaran yang diterapkan dalam bentuk bahan ajar, dalam hal ini modul dapat memberikan pengaruh yang baik. Pengaruh tersebut diantaranya mampu meningkatkan keterapilan bernalar siswa, meningkattkan kemampuan berpikir kreatif, dan meningkatkan pemahaman konsep dan kemampuan berpikir kritis siswa, menyajikan data dengan menarik dan terpercaya, memudahkan penafsiran data dan memadatkan informasi untuk meningkatkan pemahaman konsep dasar (Lestari et al., 2018). Salah satu karakteristik modul yang menyediakan corrective feedback akan berhasil membantu kesulitan belajar siswa, karena siswa akan mengatahui alasan jawaban yang salah secara lengkap (Tazkiyah et al., 2020).

\section{METODE PENELITIAN}

Jenis penelitian yang diguanakan dalam penelitian ini adalah penelitian dan pengembangan atau Reseacrh and Development (R\&D). Prosedur penelitian mengadopsi model pengembangan 4D menurut Thiaragaraja (Rochmad, 2012) yaitu model 4D. Model 4D merupakan singkatan dari Define, Design, Development and Dissemination. Kegiatan-kegiatan yang 
dilakukan pada setiap tahap pengembangan dapat dijelaskan sebagai berikut:

\section{Define (Pendefinisian)}

Kegiatan pada tahap ini dilakukan untuk menetapkan dan mendefinisikan syaratsyarat pengembangan. Dalam model lain, tahap ini sering dinamakan analisis kebutuhan. Tiap-tiap produk membutuhkan analisis yang berbedabeda. Secara umum, dalam pendefinisian ini dilakukan kegiatan analisis kebutuhan pengembangan, syarat-syarat pengembangan produk yang sesuai dengan kebutuhan pengguna serta model penelitian dan pengembangan (model $R \& D$ ) yang cocok digunakan untuk mengembangkan produk. Analisis bisa dilakukan melalui studi literatur atau penelitian pendahuluan. Kegiatan yang dilakukan pada tahap define yaitu observasi awal ke lapangan terkait dengan pembelajaran STEM dan penggunaan modul di Sekolah Menengah Pertama di Kota Cirebon, mengkaji penelitian-penelitian terdahulu terkait tentang STEM dan modul, serta analisis kurikulum dan kebutuhan peserta didik.

\section{Design (Perancangan)}

Thiagaraja (Rochmad, 2012) membagi tahap design dalam empat kegiatan, yaitu: constructing criterion referenced test, media selection, format selection, initial design. Kegiatan yang dilakukan pada tahap tersebut antara lain:
a. Pengembangan topik, yaitu penentuan pokok bahasan pembelajaran berdasarkan indikator dan tujuan yang akan dicapai
b. Perancangan layout modul
c. Perancangan design layout dan cover
d. Penyusunan draf
e. Produksi prototype 1

\section{Develop (Pengembangan)}

Pada tahap ini kegiatan yang dilakukan yaitu mengembangkan instrument penelitian yang dikembangkan dari Zulherman (2018), Sari, et al., (2017), Zaharah \& Asra (2017), Mardia \& Sundara (2020), Fajaryati, et al., (2016), Yuanita \& Kurnia (2019), dan Kasim \& Ahmad (2018). Selanjutnya melakukan penilaian atau evaluasi sendiri (self evaluation) prototipe I modul yang sudah dibuat sebelumnya dengan melihat kesesuaian modul yang dikembangkan dengan kaidah pengembangan modul yang berlaku, desain modul, penulisan dan kebahasaan yang digunakan dalam modul, serta ketepatan representasi konsep. Tujuan dari evaluasi diri ini yaitu untuk memastikan bahan ajar yang dibuat sudah baik yaitu mencakup 3 aspek berupa materi, media, dan desain (Sudirman, et al., 2018).

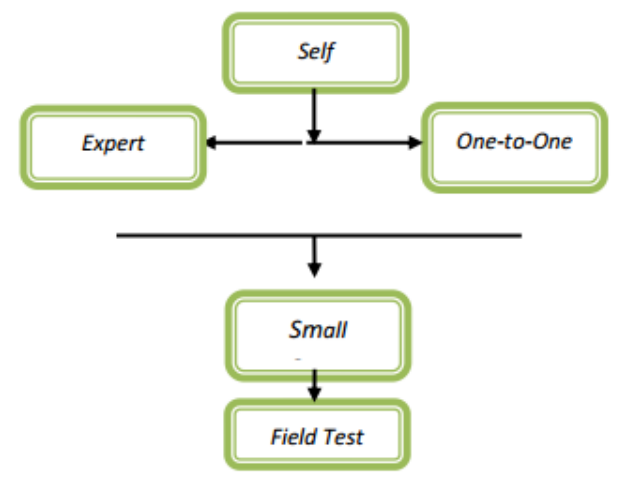

Gambar 2. Alur Desain Formative Evaluation (Tressmer dalam Sudirman, et al., 2018) Self-Evaluation (Evaluasi sendiri)

Hasil prototipe I yang telah dikembangkan pada tahap self-evaluation diberikan kepada ahli untuk divalidasi. Uji validitas yang dilakukan yaitu validasi isi, bahasa, dan desain dari prototipe 1. Para ahli diberikan lembar validasi yang sudah disusun oleh peneliti, kemudian diminta untuk menilai dan memberikan saran serta komentarnya terhadap prototipe 1 yang telah dikembangkan 
Pada lembar validasi tersebut, pernyataan sesuai diberikan bobot 1 , dan tidak sesuai diberikan bobot 0 . Hasil dari perhitungan lembar validasi kemudian direpresentasikan menurut kriteria pada Tabel 2.

Tabel 2. Interpretasi hasil validasi

\begin{tabular}{cl}
\hline Nilai Hasil Perhitungan & \multicolumn{1}{c}{$\begin{array}{c}\text { Kriteria } \\
\text { Validitas }\end{array}$} \\
\hline $0,80<\mathrm{x} \leq 1,00$ & Sangat tinggi \\
$0,60<\mathrm{x} \leq 0,80$ & Tinggi \\
$0,40<\mathrm{x} \leq 0,60$ & Sedang \\
$0,20<\mathrm{x} \leq 0,40$ & Rendah \\
$0,00<\mathrm{x} \leq 0,20$ & Sangat rendah \\
\hline
\end{tabular}

Keterangan:

$\mathrm{x}=$ Tingkat persetujuan validitas Modul (\%)

Pada tahap One to One Evaluation (Evaluasi Orang per Orang), peneliti meminta beberapa siswa SMP di kota Cirebon untuk dijadikan sampel mewakili populasi berdasarkan akreditasi sekolahnya. Pengambilan sampel dilakukan menggunakan purposive sampling. Kemudian peneliti menganalisis hasil evaluasi one to one sebagai acuan untuk merevisi prototipe 1 untuk menghasilkan prototipe 2 yang valid dan praktis.

Small Group Evaluation (Evaluasi Kelompok Kecil) merupakan tahap pengujicobaan prototipe 2 kepada kelompok kecil siswa SMP yang dipilih berdasarkan akreditasi sekolahnya. Siswa diberikan instrumen uji keterbacaan dan angket kepraktisan modul STEM.

\section{Disseminate (Penyebarluasan)}

Pada tahap ini, terdapat dua kegiatan yaitu pengujian validitas dan pengemasan, difusi dan adopsi. Bahan ajar sampai pada tahap produksi akhir jika uji pengembangan menunjukkan hasil yang konsisten dan hasil penilaian ahli merekomendasikan komentar positif.

\section{HASIL DAN PEMBAHASAN}

Hasil penelitian setiap tahap pengembangan pada penelitian ini dijelaskan sebagai berikut. Kegiatan yang dilakukan pada tahap define adalah melakukan studi pendahuluan ke sekolah terkait dengan penggunaan Modul IPA, analisis Kurikulum 2013 mata pelajaran IPA tingkat SMP, Analaisis kebutuhan peserta didik, dan mengkaji penelitian-penelitian terdahulu terkait dengan STEM dan Modul.

Hasil dari kegiatan ini adalah proposal penelitian yang diusulkan dan dibiayai untuk penelitian oleh Kementeerian Riset dan Teknologi tahun anggaran 2020. Tahap Design dimulai sejak bulan Mei 2020. Kegiatan yang dilakukan, antara lain:

1). Pengembangan topik untuk konten/ materi modul

Berdasarkan hasil kajian yang telah dilakukan, materi yang dikembangkan pada modul ini mengacu pada Kompetensi Dasar 3.5 menganalisis konsep energi, berbagai sumber energi, dan perubahan bentuk energi dalam kehidupan sehati-hari termasuk fotosintesis dan KD 4.5 Menyajikan hasil percobaan tentang perubahan bentuk energi, termasuk fotosintesis.

Kompetensi Dasar tersebut dikembangkan menjadi materi modul berdasarkan tingkat kedalaman dan keluasan materi untuk siswa kelas VII. Setelah menentukan Kompetensi Dasar, peneliti kemudian menentukan tema pengikat untuk mengkaji aspek STEM dari tema pengikat. Tema yang dipilih adalah Rumah Kincir Angin. Salah satu alasan pemilihan Rumah Kincir Angin adalah karena Cirebon merupakan salah satu Kota Pesisir yang mempunyai cukup banyak angin untuk dimanfaatkan. 
2). Perancangan layout, desain layout dan sampul modul.

Layout disusun sedemikian rupa untuk memudahkan siswa menggunakan modul secara mandiri. Dengan menggunakan modul, siswa dapat belajar secara mandiri tanpa atau dengan bimbingan guru (Setyowati, et al., 2013). Oleh sebab itu rancangan layout modul sangat penting. Modul berbasis STEM terdiri dari komponen:
a). Sampul Depan
b). Kata Pengantar
c). Deskripsi
d). Tujuan
e). Petunjuk Penggunaan Modul
f). Glosarium
g). Kegiatan Belajar
h). Uji Kemampuan Diri
j). Kunci Jawaban
k). Lembar Kerja Peserta Didik
1). Daftar Pustaka
m). Sampul Belakang

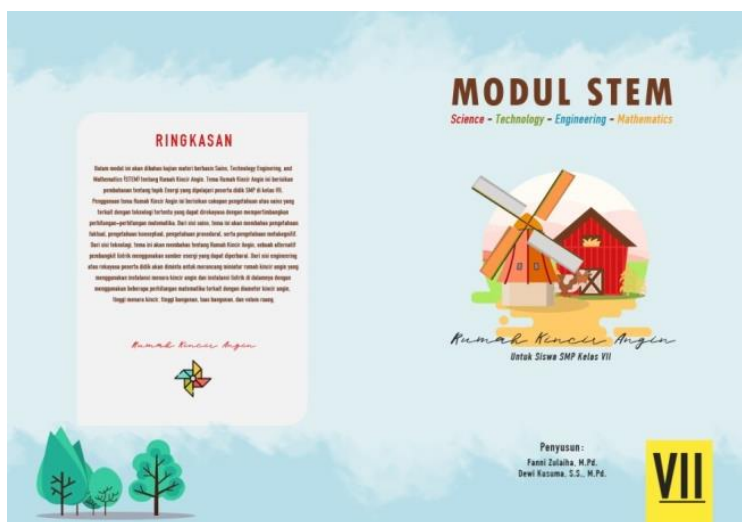

Gambar 2. Cover depan dan belakang modul

3).Penyusunan Draft Modul Berbasis STEM untuk SMP

Pada kegiatan ini peneliti menyusun materi dan kegiatan siswa ke dalam desain layout yang telah dibuat. Draft Modul ini kemudian disebut sebagai Modul Prototipe I.
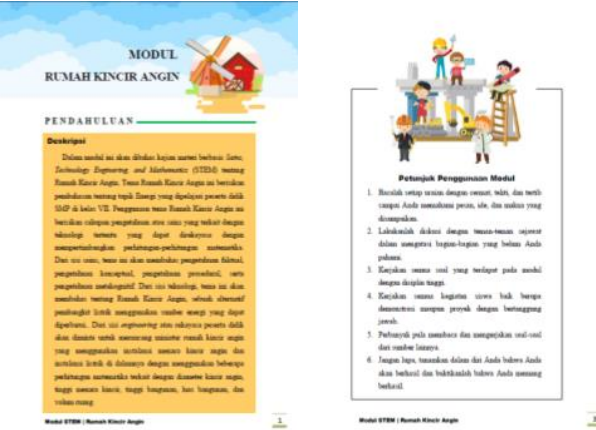

Gambar 3. Draft Modul Berbasis STEM untuk Siswa SMP

Kegiatan pada tahap development terdiri dari self evaluation, expert evaluation assessment, one to one evaluation, dan small group evaluation.

\section{1). Self Evaluation}

Self evaluation bertujuan untuk melihat kelengkapan isi dan desain modul. Kegiatan self eveluation menggunakan instrumen lembar checklist yang berisi tentang kaidah pengembangan modul yang berlaku, desain modul, penulisan dan kebahasaan yang digunakan dalam modul dan ketepatan representasi konsep. Hasil dari self assessment yaitu diperlukan perbaikan kesalahan pengetikan dan penulisan istilah-istilah yang sult dipahami. Selain itu pada lembar evaluasi belum ditemukan kunci jawaban dan pengukuran tingkat penguasaan siswa setelah mempelajari modul. Modul Prototipe 1 belum ada daftar isi dan kata pengantar. Selain itu lembar kerja siswa belum memuat secara rinci kegiatan yang harus dilakukan siswa. Kegiatan yang menggunakan analisis matematika pun belum terlihat.

\section{2). Expert Evaluation Assessment}

Expert Evaluation Assessment dilakukan oleh lima orang ahli materi dan bahasa. Masing-masing Validator mendapatkan instrumen validasi dan modul prototipe 2 , hasil revisi dari kegiatan self evaluation. Ahli materi terdiri dari 2 orang Dosen Pendidikan Fisika dan 2 orang Guru IPA 
SMP yang sudah bersertifikat profesional, dan Ahli bahasa berasal dari Dosen Bahasa Indonesia. Hasil expert evaluation assessment dapat dilihat pada Tabel 2 dan Tabel 3.

Tabel 2. Hasil Expert Evaluation Konten

\begin{tabular}{lcc}
\hline \multicolumn{1}{c}{ Aspek } & Nilai & Kriteria \\
\hline Isi & 0,86 & Sangat tinggi \\
Kelayakan isi & 0,92 & Sangat tinggi \\
Desain & 1,00 & Sangat tinggi \\
\hline
\end{tabular}

Tabel 3. Hasil Expert Evaluation Bahasa

\begin{tabular}{|c|c|c|}
\hline Indikator & $\begin{array}{c}\text { Nilai Hasil } \\
\text { Perhitungan }\end{array}$ & $\begin{array}{c}\text { Kriteria } \\
\text { Validitas }\end{array}$ \\
\hline $\begin{array}{l}\text { Kejelasan } \\
\text { Informasi }\end{array}$ & 1 & Sangat tinggi \\
\hline $\begin{array}{l}\text { Kesesuaian dengan } \\
\text { kaidah Bahasa } \\
\text { Indonesia }\end{array}$ & 1 & Sangat tinggi \\
\hline $\begin{array}{l}\text { Penggunaan bahasa } \\
\text { secara efektif dan } \\
\text { efisien }\end{array}$ & 1 & Sangat tinggi \\
\hline $\begin{array}{l}\text { Hasil expert } \\
\text { bahasa menunj } \\
\text { dengan kriteria } \\
\text { menandakan b } \\
\text { dikembangkan } \\
\text { (Khoirudin, 20 }\end{array}$ & $\begin{array}{l}\text { evaluation } \\
\text { ukkan nilai } \\
\text { sangat tinggi } \\
\text { ahwa modul } \\
\text { telah dapat } \\
\text { 19). }\end{array}$ & $\begin{array}{l}\text { onten dan } \\
86-1,00 \\
\text { Kriteria ini } \\
\text { yang telah } \\
\text { digunakan }\end{array}$ \\
\hline
\end{tabular}

\section{3). One to One Evaluation}

Kegiatan evaluasi orang per orang dilakukan secara online yaitu dengan wawancara masing-masing Siswa menggunakan video call. Siswa diberikan modul dan diberi tugas untuk membaca dan mempelajarinya. Jumlah partisipan yang terlibat berjumlah 10 orang, 5 orang siswa berasal dari salah satu sekolah berakreditasi A dan 5 orang lainnya berasal dari salah satu sekolah berakreditasi B. Hasil dari kegiatan One to One Evaluation yaitu $90 \%$ siswa merasa tampilan modul menarik, sehingga meningkatkan minat Siswa untuk mempelajari modul. Hal ini sesuai dengan hasil penelitian Kurniawan, et al., (2020). Teks atau tulisan pada modul mudah untuk dibaca. Gambar-gambar yang disajikan memberikan kemudahan dalam memahami materi. Tata letak pada modul memudahkan siswa untuk mempelajari materi secara runut (Endarwati \& Widjajanti, 2016). Pada aspek penyajian materi, sebanyak $70 \%$ siswa menjawab modul ini mudah dimengerti sehingga kegiatan dapat dilakukan dengan mudah. Adapun siswa yang merasa kesulitan dalam mempelajari modul ini disebabkan karena tidak memahami instruksi/ perintah pada modul. Hal ini menjadi catatan bagi peneliti untuk memperbaiki redaksi kalimat, agar semua tingkatan siswa dapat menggunakan modul ini dengan baik. Aspek kepraktisan, sebanyak 90\% siswa menjawab modul ini dapat membantu mereka dalam memahami konsep energi. Siswa juga tertarik dan termotivasi menggunakan modul berbasis STEM ini. Hal ini sesuai dengan hasil penelitian Kurniawan, et al., (2020) yang menyatakan bahwa penggunaan modul dapat meningkatkan motivasi belajar siswa. Siswa berharap modul berbasis STEM ini dikembangkan lagi untuk pembelajaran IPA materi lainnya.

\section{4). Small Group Evaluation}

Kegiatan Small Group Evaluation dilakukan secara daring. Ketua peneliti mengikuti pembelajaran secara daring di kelas Google Classroom yang telah dibuat oleh Guru Mata Pelajaran IPA kelas VIII di 2 sekolah tempat penelitian. Setelah Siswa menggunakan Prototipe 2 Modul berbasis STEM, siswa diminta untuk mengisi angket yang sudah peneliti buat dalam bentuk google form.

Tabel 4. Tabel Hasil Small Group Evaluation

\begin{tabular}{ccc}
\hline \multicolumn{1}{c}{ Aspek } & $\begin{array}{c}\text { Rata-Rata } \\
\text { Skor Angket }\end{array}$ & Kategori \\
\hline Keterbacaan & 87 & Sangat Kuat \\
Kepraktisan & 80 & Kuat \\
\hline
\end{tabular}

Berdasarkan Tabel 4, diketahui bahwa rata-rata hasil uji keterbacaan $87 \%$ termasuk ke dalam kriteria interpretasi sangat kuat (Riduwan, 2015). Hasil ini menunjukkan secara keseluruhan modul 
yang telah dikembangkan sudah baik untuk digunakan (Khoirul, 2019). Ratarata uji kepraktisan yaitu $80 \%$ termasuk ke dalam kriteria interpretasi kuat (Riduwan, 2015). Didapatkan pula masukan-masukan dari Siswa yang telah menggunakan Modul prototipe 2, diantaranya adalah tulisan lebih besar, agar lebih mudah dibaca, penjelasan materi dibuat lebih singkat, perbanyak kegiatan siswa, ditambahkan gambargambar agar semakin mudah dan jelas, dan dikembangkan lagi untuk materi pembelajaran IPA lainnya. Kejelasan tulisan dan ilustrasi, contoh dan latihan memudahkan siswa untuk mempelajari materi dan menunjang keberhasilan proses belajar. (Endarwati \& Widjajanti, 2016; Pratiwi, 2014).

\section{PENUTUP}

Modul berbasis STEM hasil pengembangan penelitian dikatakan valid dan layak berdasarkan hasil validasi expert judgment dengan nilai validasi konten sebesar 0,93 dengan kategori sangat tinggi, nilai validasi bahasa 1,00 dengan kategori sangat tinggi, dan berdasarkan hasil uji keterbacaan dan kepraktisan kepada siswa diperoleh nilai $87 \%$ dengan kategori sangat kuat untuk uji keterbacaan dan $80 \%$ dengan kategori kuat untuk uji kepraktisan. Modul berbasis STEM ini juga dapat memotivasi siswa dalam mempelajari materi IPA.

\section{UCAPAN TERIMAKASIH}

Penulis mengucapkan terimakasih pada Direktorat Riset dan Pengabdian Masyarakat Kementerian Riset dan Teknologi/ Badan Riset dan Inovasi Nasional sebagai pemberi dana.

\section{REFERENSI}

Arnyana, I, B, P. (2018). Pembelajaran Sains di Era Revolusi Industri 4.0. Prosiding Seminar Nasional MIPA (8).
Bybee, R, W. (2013). The case for STEM education: Challenges and opportunity. Arlington, VI: National Science Teachers Association (NSTA) Press.

Chingos, M, W., \& Whitehurst, G, J. (2012). Choosing Blindly: instructional materials teacher effectiveness and the common core. Washington: Brown Center on Education Policy at Brookings.

Depdiknas. (2007). Pengembangan Modul. Jakarta: Depdiknas.

Dewi, W, A, F. (2020). Dampak COVID-19 terhadap implementasi pembelajaran daring di sekolah dasar. EDUKATIF: Jurnal Ilmu Pendidikan, 2(1).

Endarwati, E.D. \& Widjajanti, D.B. (2016). Peningkatan Motivasi Belajar dan Prestasi Belajar Operasi Hitung Bilangan Bulat Siswa Kelas 4 Melalui Media Visual Interaktif. Jurnal Penelitian Ilmu Pendidikan. 9(1), 5369.

Fajaryati, N., Nurkhamid, Pranoto, P.W., Muslikhin, \& Dwi, A. (2016). EModule Development for the Subject of Measuring Instruments and Measurement in electronics Engineering Education. Jurnal Pendidikan Teknologi dan Kejuruan, 23 (2), 191-199

Gullford, J, P. (1956). Fundamental Statistics in Phsychology and Education. New York: Mc. GrawwHill Book Co. Ind.

Kasim, N.H. \& Ahmad, C.N.C. (2018). PRO-STEM Module: The Development and Validation. International Journal of Academic Research in Business and Social Sciences, 8 (1), 728-739

Keputusan Menteri Pendidikan dan Kebudayaan Republik Indonesia Nomor 719/P/2020 tentang Pedoman Pelaksanaan Kurikulum pada Satuan Pendidikan dalam Kondisi Khusus. 
Khoirudin, M. (2019). Pengembangan Modul Pembelajaran IPA Biologi Berbasis Scientific Approach Terintegrasi Nilai Keislaman Pada Materi Interaksi Antar Makhluk Hidup Dengan Lingkungan. IJIS Edu : Indonesian Journal of Integrated Science Education, 1(1), 33-42. doi:http://dx.doi.org/10.29300/ijisedu. v1i1.1403

Kurniawan, A. R., Budiono, H., Hariandi, A., Marlina, M., Kurniawati, E. F., Meidiawati, R., \& Piyana, S. O. (2020). Investigasi Minat Belajar Terhadap Modul Elektronik Berbasis Etnokontruktivisme. Profesi

Pendidikan Dasar, 7(1), 93-104. doi: https://doi.org/10.23917/ppd.v1i1.106 50

Lestari, D., Astuti, B., \& Darsono, T. (2018). Implementasi LKS Dengan Pendekatan STEM (Science, Technology, Engineering, And Mathematics) Untuk Meningkatkan Kemampuan Berpikir Kritis Siswa. Jurnal Pendidikan Fisika dan Teknologi, 4(2), 202-207. doi:http://dx.doi.org/10.29303/jpft.v4i $\underline{2.809}$

Mardia, A \& Sundara, V.Y. (2020). Pengembangan Modul Program Linier Berbasis Pembelajaran Mandiri. Edumatika: Jurnal Pendidikan Matematika, 10 (1), 10-18

Milaturrahman, N., Mardiyana, M., \& Pramudya, I. (2017). Mathematics Learning Process with Science, Technology, Engineering, Mathematics (STEM) Approach in Indonesia. Journal of Physics: Conference Series (895), from doi :10.1088/1742-6596/895/1/012030.

Pratiwi, N.K. (2015). Pengaruh Tingkat Pendidikan, Perhatian Orang Tua, dan Minat Belajar Siswa terhadap Prestasi Belajar Bahasa Indonesia Siswa SMK Kesehatan di KotaTangerang. Jurnal Pujangga. 1 (2), 75-105.
Riduwan. (2015). Skala Pengukuran Variabel-Variabel Penelitian. Bandung: Alfabeta.

Rochmad, R. (2012). Desain Model Pengembangan Perangkat Pembelajaran Matematika. Kreano, Jurnal Matematika Kreatif-Inovatif, 3(1), 59-72. doi:https://doi.org/10.15294/kreano.v 3i1.2613

Rustaman, N, Y. (2016). Pembelajaran Sains Masa Depan Berbasis STEM Education. Prosiding Seminar Nasional Biologi Edukasi. STKIP PGRI Sumatera Barat.

Sari, W., Jufrida, \& Pathoni Haerul. (2017). Pengembangan Modul Elektronik Berbasis 3D Pageflip Professional pada Materi Konsep Dasar Fisika Inti dan Struktur Inti. Jurnal EduFisika, 2 (1), 38-50.

Setiawan, A. R., \& Mufassaroh, A. Z. (2020, May 26). Lembar Kegiatan Siswa untuk Pembelajaran Jarak Jauh Berdasarkan Literasi Saintifik pada Topik Penyakit Coronavirus 2019 (COVID-19).

https://doi.org/10.31237/osf.io/7tngk

Setyowati, R., Parmin, \& Widiyatmoko, A. (2013). Pengembangan Modul IPA Berkarakter Peduli Lingkungan Tema Polusi sebagai Bahan Ajar Siswa SMK N 11 Semarang. Unnes Science Education Journal (2).

Smaldino, S, E., Lowther, D, L, \& Rusell, D. (2014). Instructional Technology \& Media for Learning: Teknologi Pemeblajaran dan Media untuk Belajar. Jakarta: Kencana.

Sudirman., Kristiono., \& Taufiq. (2018). Pengembangan Modul Mata Kuliah Gelombang Berbasis STEM (Science, Technology, Engineering and Mathematics) Pada Program Studi Pendidikan Fisika. Jurnal Inovasi dan Pembelajaran Fisika, 5(2). 
Surat Edaran Nomor 15 Tahun 2020 tentang Pedoman Penyelenggaraan Belajar Dari Rumah.

Tazkiyah, A., Sulur, S., \& Fawaiz, S. (2020). Pengembangan Modul Elektronik Dengan Feedback Berbasis Android Materi Suhu Dan Kalor Untuk Siswa SMA/MA. Jurnal Pendidikan Fisika dan Teknologi, 6(1), 31-38. doi:http://dx.doi.org/10.29303/jpft.v6i 1.1731

Yoda, I, K., Kanca, \& Wijaya, M, A. (2011). Pengembangan Modul Bermuatan Model Pembelajaran Bandura untuk Meningkatkan Hasil Belajar Penjasorkes dan Kecerdasan Kinestetik Siswa Sekolah Dasar. Jurnal Pendidikan Jasmani Kesehatan dan Rekreasi 5(3): 341-376.

Yuanita \& Kurnia, F. (2019). Pengembangan Bahan Ajar Berbasis STEM (Science, Technology, Engineering, and Mathematics) Materi Kelistrikan untuk Sekolah Dasar. Jurnal Profesi Pendidikan Dasar, 6 (2), 199-210

Zaharah, Yelianti, U., \& Asra, R. (2017). Pengembangan Modul Elektronik dengan Pendekatan Saintifik Materi Sistem Peredaran Darah pada Manusia untuk Siswa kelas VIII. Edu-Sains, 6 (1), 26-33

Zulherman. (2018). Pengembangan Modul Pembelajaran Fisika Sekolah Menengah pada Materi Gelombang. Formatif: Jurnal Ilmiah Pendidikan MIPA, 8 (2), 143-148 